\title{
Performance Analysis of Path loss Prediction Models in Wireless Mobile Networks in Different Propagation Environments
}

\author{
Aymen Zreikat, Milan Dordevic \\ American University of the Middle East (AUM), College of Engineering \\ Egaila, Kuwait \\ aymen.zreikat@aum.edu.kw; milan.dordevic@aum.edu.kw
}

\begin{abstract}
For the new generation of mobile networks, innovative prediction models with extended frequencies are needed. The goal of this paper is to analyze six different path loss prediction models: free space, extended COST-231 Hata, empirical Hata, Walfisch-Ikegami, Stanford University Interim (SUI) and Ericson (9999). The article shows that SUI, Ericsson and Empirical Hata are overall the best choice for the new generation of mobile networks regardless of distance and type of environment. However, SUI outperforms Ericsson and Empirical Hata for $3.5 \mathrm{GHz}$ for both urban and suburban environments. For higher frequencies $(28 \mathrm{GHz})$, which is needed for the new generation of mobile networks like $5 \mathrm{G}$, it is shown that Ericsson model gives better results for path loss in urban compared with SUI which gives better results in suburban environment. This conclusion is confirmed by introducing the average of path loss.
\end{abstract}

Keywords: performance analysis; path loss; propagation environments; wireless mobile networks; prediction models

\section{Introduction}

In wireless communications, the signal is transmitted by electromagnetic waves to a receiver which currently suffers from propagation [1]. The signal is radiated by a transmitter and may also travel along many different paths to a receiver simultaneously. This effect is called multipath. Multipath waves are combined at the receiver antenna. The difference of signal strengths from transmitter to receiver antenna is termed as path loss (PL). PL at destination is generally determined by the use of different models i.e., stochastic, deterministic and empirical [2][3][4][5][6]. Propagation models can be classified mainly into two types: fully empirical models and deterministic models. There are some models that have the characteristics of both types. Those are known as semi-empirical models. Empirical models are based on practically measured data. Since few parameters are used, these empirical models are simple but not very accurate. Some models are categorized as empirical models for macro cellular environment. These include Hata model, Okumura model, and COST231 Hata model. Extended COST-231 Hata model has been approved by the European Cooperation in the field of the scientific and Technical Research (COST) to represent higher frequencies [7]. It uses a propagation equation split up into two terms; the first term has a logarithmic dependence on distance, $\mathrm{d}$; thesecond term is directly independent of distance. It also includes adjustments to the basic equation for urban, suburban, dense-urban, and rural propagation losses. The complete derivation of these equations has been done in [8]. Additionally, deterministic models are very accurate. Some of the examples include Ray Tracing and Ikegami model. As mentioned earlier, semi-empirical models are based on both empirical data and deterministic aspects. In addition the Cost-231 Walfisch-Ikegami model is categorized as a semiempirical model. All of these models estimate the mean PL based on parameters including but not restricted to only antenna heights of the transmitter and receiver as well as distance between them,. Most of these models have been extensively validated to be used for the new generation of mobile networks (i.e. UMTS, WIMAX/WIFI and LTE). Some of them are based on systematic interpretation of measurement data obtained in the service area [9][10][11][12][13]. Researchers have conducted studies of some of the empirical models that are suitable for PL prediction in mobile as well as fixed wireless systems like WiMAX [14]. They compared measured data with those obtained by four prediction models: SUI model, COST 231 Hata, Macro Model and Model 9999. A separate analysis for location with NLOS and LOS propagation conditions was also made. The introduced results as seen in [15] are obtained based on distance up to around 7 
$\mathrm{km}$, while the presented results in this research paper are showing findings involving distance up to $40 \mathrm{~km}$. Moreover, the results are based on received level compared to the path loss results which are presented in Section 3.

Researchers have recently performed a study in which a Radio Propagation Path Loss Models for 5G Cellular Networks in the $28 \mathrm{GHz}$ and $38 \mathrm{GHz}$ Millimeter-Wave Bands have been presented [16]. The proposed models estimated a path loss data in both heavy and light urban areas. By using the $28 \mathrm{GHz}$ propagation models, they simulate the frequency coverage for 5G cellular networks. In [17], the path losses in cells have been compared with theoretical path loss models: Cost231 Hata, SUI, ECC33 and Cost231 Walfisch-Ikegami. The obtained results, when compared with theoretical values from the theoretical models, demonstrated the closest consistency with the predicted readings by the Hata model in terms of path loss. Moreover, it is shown that Cost231 Hata's model is chosen and optimized for suburban outdoor coverage operating in $2.375 \mathrm{GHz}$ frequency band.

The rest of the paper is organized as follows: In Section 2, we introduce different radio propagation models; Section 3 presents our main comparative results and discussions and finally, in Section 4 we present our concluding remarks followed by the acknowledgement and the references.

\section{Radio Propagation Models}

\subsection{Free space model}

A path loss in Free Space $L$ defines how much strength of signal is lost during propagation from transmitter to receiver. Free Space Model is diverse on frequency and distance. It is calculated by using Eq. (1).

$$
\mathrm{L}=32.45+20 \log (\mathrm{d})+20 \log (\mathrm{f})
$$

Where, $f$ is the Frequency in $(\mathrm{MHz})$ and $\mathrm{d}$ is the distance in $(\mathrm{Km})$.

\subsection{Extended COST-231 Hata model}

Extended COST-231 Hata model uses a propagation equation which is divided into two terms. The first term has a logarithmic dependence on distance, $d$, while a second term is independent of distance. It also includes adjustments to the basic equation to account for urban, suburban, dense-urban, and rural propagation losses. The complete derivation of these equations has been done in [10].

The general propagation loss in $d B$ is given by [4] and shown by using Eq. (2).

$$
\mathrm{Lp}=46.30+33.9 * \log (\mathrm{f})-13.82 * \log (\mathrm{hm})-\mathrm{a}(\mathrm{hm})+\left(44.9-6.55^{*} \log (\mathrm{hb})\right) * \log (\mathrm{d})+\mathrm{Cm}
$$

Where,

$L p$ is a propagation loss in environment of type $p$, in $d B$ (0: Urban, 1: Suburban, 2: Dense-urban, 3: Rural).

$f$ is the frequency of the transmission in $M H z$.

$\mathrm{hm}$ is the height of the mobile or receiver in meters $(1-10 \mathrm{~m})$.

$h b$ is the height of the base station or transmitter in meters $(30-200 m)$

$d$ is the distance between the receiver and the transmitter in kilometres $(1-20 \mathrm{~km})$.

$a(\mathrm{hm})$ is a mobile antenna correction factor which different for each environment.

$\mathrm{Cm}$ is the correction factor which has different value for each environment. As we can observe, the path loss in the free space model depends on the frequency and distance. Although, further parameters are introduced in other propagation models, such as the height of the mobile, $h m$, and the height of the base station, $h b$. Additionally,

The range of value for the validity of Hata model is [18]:

$150 \leq f \leq 1500 \mathrm{MHz}, 30 \leq h b \leq 200 \mathrm{~m}, 1 \leq \mathrm{hm} \leq 10 \mathrm{~m}$ and $1 \leq d \leq 20 \mathrm{~km}$.

There, the values of the height of the mobile and the height of the base station are fixed within the given ranges for the sake of comparison.

Extended COST-231 Hata for Urban environment:

$$
\mathrm{a}(\mathrm{hm})=(1.1 * \log (\mathrm{f})-0.7) *(\mathrm{hm})-(1.56 * \log (\mathrm{f})-0.8) \mathrm{dB}
$$


and $C m=0$. Extended COST-231 Hata for Suburban environment:

$$
\mathrm{L}_{1}=\mathrm{L}_{0}-2 *\left(\log \left(\frac{\mathrm{f}}{28}\right)\right)^{2}-5.4
$$

Where,

$$
\mathrm{a}(\mathrm{hm})=(1.1 * \log (\mathrm{f})-0.7) *(\mathrm{hm})-(1.56 * \log (\mathrm{f})-0.8) \mathrm{dB}
$$

and $\mathrm{Cm}=0$.Extended COST-231 Hata for dense-urban environment:

$$
\mathrm{a}(\mathrm{hm})=\left(3.2 *\left(\log (11.75 * \mathrm{hm})^{2}-4.97\right)\right) \mathrm{dB}
$$

and $\mathrm{Cm}=3$. Extended COST-231 Hata for rural environment:

$$
\mathrm{L}_{3}=\mathrm{L}_{0}-4.78 *(\log (\mathrm{f}))^{2}+18.33 * \log (\mathrm{f})-40.94
$$

\subsection{Empirical Hata Model}

Similar to COST-231, Hata empirical model uses a similar propagation equation split up. The Hata model also includes adjustments to the basic equations to account for urban, suburban and open area propagation losses. For more detail see reference [1]. The variables are described in the attachments at the end of the paper.

The Hata equation for propagation loss in an urban area is given by:

$$
\mathrm{L}_{\mathrm{p}}=69.55+26.16 * \log (\mathrm{f})-13.82 * \log (\mathrm{hb})-\mathrm{a}(\mathrm{hm})+(44.9-6.55 * \log (\mathrm{hb})) * \log (\mathrm{d})
$$

Where, in the case of propagation loss in a medium to small city:

$$
a(h m)=(1.1 * \log (f)-0.7) *(h m)-(1.56 * \log (f)-0.8)
$$

The adjustment for propagation loss in a suburban area is:

$$
\mathrm{L}_{\mathrm{ps}}=\mathrm{L}_{\mathrm{p}}(\text { urban area })-2 *(\log (\mathrm{f} / 28))^{2}-5.4
$$

The adjustment for propagation loss in an open area is:

$$
\mathrm{L}_{\mathrm{p} 0}=\mathrm{L}_{\mathrm{p}}(\text { urban })-4.78 *(\log (\mathrm{f}))^{2}+18.33 * \log (\mathrm{f})-40.94
$$

\subsection{Walfisch-Ikegami propagation model}

This model assumed only the building on the vertical plane. However, this model is considered to have a high accuracy especially in urban environments. The main parameters of the model as was shown in [7] are:

$f$ is Frequency $(800-2000 \mathrm{MHz})$.

$h_{\text {mobile }}$ is height of the transmitter $(4-50 m)$.

$h_{\text {base }}$ is height of the receiver $(1-3 m)$.

$R$ is distance between transmitter and receiver, $(20-5000 m)$.

$w$ is the average of widths of streets.

$b$ is the average of building separation.

If a free LOS exists in a street canyon then, path loss defined as:

$$
L_{L O S}=42.6+26 * \log (\mathrm{R})+20 * \log (\mathrm{f}) \quad \text { for } \mathrm{R} \geq 20 \mathrm{~m}
$$


If a non-LOS exists, path loss defined as follow:

$$
\mathrm{L}_{\mathrm{b}}=\left\{\begin{array}{l}
\mathrm{L}_{\mathrm{fs}}+\mathrm{L}_{\mathrm{rts}}+\mathrm{L}_{\mathrm{msd}} \\
\mathrm{L}_{\mathrm{fs}}
\end{array} \text { if } \mathrm{L}_{\mathrm{rts}}+\mathrm{L}_{\mathrm{msd}}<0\right.
$$

$\mathrm{L}_{\mathrm{fs}}$ represents free space loss, $\mathrm{L}_{\mathrm{rts}}$ rooftop to street diffraction and scatter loss, $\mathrm{L}_{\mathrm{msd}}$ is the multiscreen loss. The rooftop to street diffraction and scatter loss $\mathrm{L}_{\mathrm{rts}}$ represents the coupling of wave propagating along the multi-screen path into the street mobile located.

$$
\mathrm{L}_{\mathrm{rts}}=169-10 * \log (\mathrm{w} / \mathrm{m})+10 * \log (\mathrm{f} / \mathrm{MHz})+20 * \log \left(\mathrm{h}_{\mathrm{m}}\right)+\mathrm{L}_{\text {ori }}
$$

Where $L_{\text {ori }}$ is defined as:

$$
\mathrm{L}_{\text {ori }}=\left\{\begin{array}{lc}
-10+0.345 \varphi & \text { for } 0^{0} \leq \varphi \leq 35^{0} \\
2.5+0.075\left(\varphi-35^{0}\right) & \text { for } 35^{0} \leq \varphi \leq 55^{0} \\
4-0.114\left(\varphi-55^{0}\right) & \text { for } 55^{0} \leq \varphi \leq 90^{0}
\end{array}\right.
$$

and $\varphi$ is the angle between incidences coming from base station and road in degrees.

$$
\begin{gathered}
\Delta h_{\text {mobile }}=\Delta h_{\text {roof }}-\Delta h_{\text {mobile }} \\
\Delta h_{\text {base }}=\Delta h_{\text {base }}-\Delta h_{\text {roof }}
\end{gathered}
$$

The multiscreen diffraction loss $\mathrm{L}_{\mathrm{msd}}$ is an integral for which Walfisch-Bertoni model approximate a solution to this for the cases base station antenna height is greater than the average rooftop. COST 231 extended this solution to the cases base station antenna height is lower than the average rooftop by including empirical functions.

$$
\mathrm{L}_{\mathrm{msd}}=\mathrm{L}_{\mathrm{bsk}}+\mathrm{k}_{\mathrm{a}}+\mathrm{k}_{\mathrm{d}} * \log (\mathrm{d} / \mathrm{km})+\mathrm{k}_{\mathrm{f}} * \log (\mathrm{f} / \mathrm{MHz})-9 * \log (\mathrm{b} / \mathrm{m})
$$

In this expression, $\mathrm{b}$ is the average building separation, $L_{b s h}$ is shadowing gain (negative loss) that occurs when the base station antenna is higher than the rooftops:

$$
\mathrm{L}_{\text {bsk }}= \begin{cases}-18 * \log 10\left(1+\Delta \mathrm{h}_{\text {base }}\right) & \text { for } \mathrm{h}_{\text {base }}>\mathrm{h}_{\text {roof }} \\ 0 & \text { for } \mathrm{h}_{\text {base }} \leq \mathrm{h}_{\text {roof }}\end{cases}
$$

$k_{d}$ is the distance factor and it is given by:

$$
\mathrm{k}_{\mathrm{d}}= \begin{cases}18 & \text { for } \mathrm{h}_{\text {base }}>\mathrm{h}_{\text {roof }} \\ 18-\frac{15 * \Delta \mathrm{h}_{\text {base }}}{\mathrm{h}_{\text {roof }}} & \text { for } \mathrm{h}_{\text {base }} \leq \mathrm{h}_{\mathrm{roof}}\end{cases}
$$

$k_{a}$ is the multiscreen diffraction loss and given by: 


$$
\mathrm{k}_{\mathrm{a}}=\left\{\begin{array}{cl}
54 & \text { for } \mathrm{h}_{\mathrm{base}}>\mathrm{h}_{\text {roof }} \\
54-0.8 * \Delta \mathrm{h}_{\text {base }} & \text { for } \mathrm{R}>0.5 \mathrm{~km} \text { and } \mathrm{h}_{\text {base }} \leq \mathrm{h}_{\text {roof }} \\
54-0.8 * \Delta \mathrm{h}_{\text {base }} * \frac{\mathrm{R}}{0.50} & \text { for } \mathrm{R}<0.5 \mathrm{~km} \text { and } \mathrm{h}_{\text {base }} \leq \mathrm{h}_{\text {roof }}
\end{array}\right.
$$

for medium sized cities and suburban centres with moderate tree density.

The frequency factor, $k_{f}$

$$
\mathrm{k}_{\mathrm{f}}=-4+\left\{\begin{aligned}
0.7 *\left(\frac{\mathrm{f}}{925}-1\right) & \text { for MS } \\
1.5 *\left(\frac{\mathrm{f}}{925}-1\right) & \text { for MC }
\end{aligned}\right.
$$

Where, $M S$ stands for medium sized cities and suburban centres with moderate tree density, while $M C$ stands for Metropolitan Centres. The term $k_{a}$ denotes the increase of the path loss for base station antennas below the rooftops of adjacent buildings. The terms $k_{d}$ and $k_{f}$ control the dependence of the multi-screen diffraction loss versus distance and radio frequency.

\subsection{Stanford University Interim (SUI) Model}

Stanford model is an extension to Hata model with additional correction parameters to cover frequencies above 1.9 $\mathrm{GHz}$. Therefore, this model has been proposed in the literature as a solution for the planning of WiMAX/LTE network on a $3.5 \mathrm{GHz}$ band [14][15]. SUI model can be used for a base station antenna height from $10 \mathrm{~m}$ to $80 \mathrm{~m}$, the receiving antenna height from 2 to $10 \mathrm{~m}$ and a cell radius from $0.1 \mathrm{~km}-8 \mathrm{~km}$ [16]. What is significant in this model is the existence of the random variables, path loss exponent, $\gamma$ and fading standard deviation, $\mathrm{s}$. The model has three types of terrain called A, B and C. Type A represents a terrain with highest path loss and can be used for hilly areas. Type B is used for flat terrain. On the other hand, Type $\mathrm{C}$ is used for flat terrains with high vegetation where path loss is the lowest. The basic expression for the path loss for SUI model is:

$$
\mathrm{L}=\mathrm{A}+10 * \gamma * \log \left(\frac{\mathrm{d}}{\mathrm{d} 0}\right)+\mathrm{X}_{\mathrm{f}}+\mathrm{X}_{\mathrm{h}}+\mathrm{s} \quad \text { for } \mathrm{d}>\mathrm{d} 0
$$

Where,

$d$ (in meters ) is the distance between the base station and the antenna.

$d_{0}=100$

$X_{f}$ is the correction for frequency above $2 \mathrm{GHz}$.

$X_{h}$ is the correction for the receiver Antenna Height.

$s$ is the correction for shadowing effect.

$\gamma$ is the Path loss component which is given in [14] as:

$$
\gamma=\mathrm{a}-\mathrm{b} * \mathrm{~h}_{\mathrm{b}}+\frac{\mathrm{c}}{\mathrm{h}_{\mathrm{b}}}
$$

The value of $\gamma$ depends on the environment type. For urban area, the path loss component $\gamma=2$, in urban NLOS environment: $3<\gamma>5$, and for indoor propagation $\gamma>5$. Where $h_{b}$ is the base station antenna height in meters a, b and $\mathrm{c}$ are constants dependent on the terrain type. Terrain types for SUI model is given in Table 1. 
Table 1: Terrain types for SUI model.

\begin{tabular}{|c|c|c|c|}
\hline Param & Terrai & Terra & Terrai \\
\hline $\mathrm{a}$ & 4.60 & 4.00 & 3.60 \\
\hline $\mathrm{b}(\mathrm{m}-1)$ & 0.0075 & 0.006 & 0.005 \\
\hline $\mathrm{c}(\mathrm{m})$ & 12.60 & 17.10 & 20.0 \\
\hline
\end{tabular}

Parameter $\mathrm{A}$ is given as:

$$
\mathrm{A}=20 * \log _{10}\left(\frac{4 \pi \mathrm{d}_{0}}{\lambda}\right)
$$

Where, $\lambda$ is the wave length expressed in meters.

The correction factors for the operating frequency and for the receiver antenna height for the model are:

$$
\begin{gathered}
\mathrm{X}_{\mathrm{f}}=6.0 * \log \left(\frac{\mathrm{f}}{2000}\right) \text { and } \\
\mathrm{X}_{\mathrm{h}}=-10.8 * \log \left(\frac{\mathrm{h}_{\mathrm{r}}}{2000}\right) \text { for Terrain A and B. } \\
\mathrm{X}_{\mathrm{h}}=-20 * \log \left(\frac{\mathrm{h}_{\mathrm{r}}}{2000}\right) \text { for Terrain C. }
\end{gathered}
$$

Where, $f$ is the frequency in $M H z$, and $h_{r}$ is the receiver height in meters. The SUI model is used for urban, suburban and rural environments.

\subsection{Ericsson (9999) Model}

This model is an extension of Hata Okumura model to be used for higher frequencies (i.e. higher than $3 \mathrm{GHz}$ ). Sometimes, it is called 9999 model [14]. The path loss expression is:

$$
\mathrm{Lp}=\mathrm{a} 0+\mathrm{a} 1 * \log (\mathrm{d})+\mathrm{a} 2 * \log \left(h_{b}\right)+\mathrm{a} 3 * \log \left(h_{b}\right) * \log (\mathrm{d})-3.2 *\left(\log \left(11.75 * h_{m}\right)\right)^{2}+\mathrm{g}(\mathrm{f})
$$

Where:

$$
g(f)=44.49 * \log (f)-4.78 *(\log (f))^{2}
$$

and $\mathrm{a} 0, \mathrm{a} 1, \mathrm{a} 2$ and $\mathrm{a} 3$ values are given in Table 2:

Table 2: Ericksson model parameters [15].

\begin{tabular}{|c|c|c|c|c|}
\hline & $\mathbf{a}_{\mathbf{0}}$ & $\mathbf{a}_{\mathbf{1}}$ & $\mathbf{a}_{\mathbf{2}}$ & $\mathbf{a}_{\mathbf{3}}$ \\
\hline Urba & 36. & 30. & 12. & 0.1 \\
\hline Sub & 43. & 68. & 12. & 0.1 \\
\hline
\end{tabular}

\section{Comparative results and Discussions}

The presented results of analysis are generated using MATLAB. For each of the case, two figures are generated; the first in urban and the second is suburban environments. All figures are generated for path loss against distance. It can be noticed from Figure 1 and 2 that SUI model is the best among all models for both environments even with lower frequency $(f=1.5 \mathrm{GHz})$. Besides, for suburban environment, it can be noticed that the Empirical Hata gives better results than Ericsson model (i.e. Figure 2). The same behaviour can be noticed in Figure 3 and 4 where higher frequency is used (i.e. $f$ $=3.5 \mathrm{GHz}$ ). In figures 5 and 6 , the same behaviour is investigated but with different distance. Again, it is shown that SUI and Ericsson model are the best choice even for longer distance between the transmitter and the receiver especially for urban environment. Moreover, for suburban environment, SUI and Empirical Hata will be the best choice. 


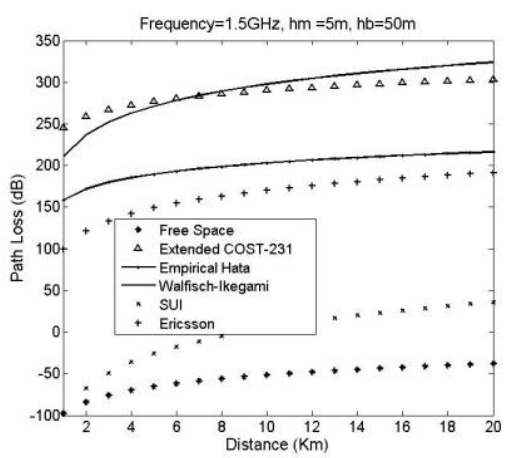

Fig. 1: Path loss against distance - urban.

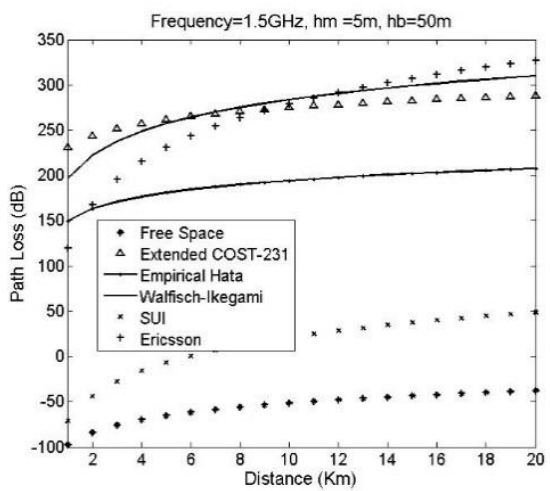

Fig. 2: Path loss against distance - suburban.

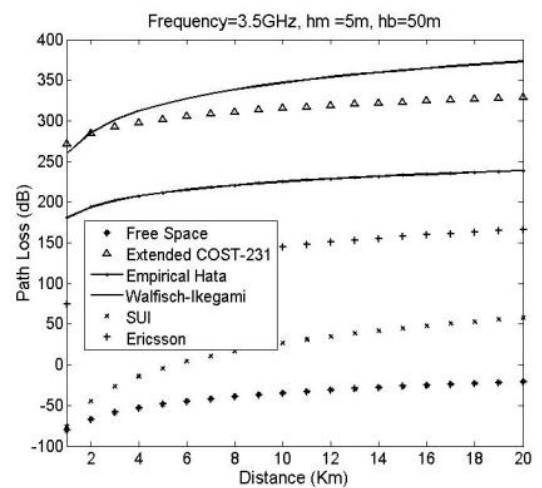

Fig. 3: Path loss against distance - urban.

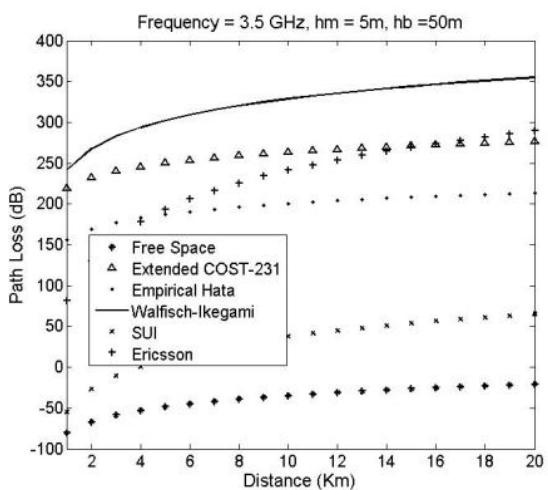

Fig. 4: Path loss against distance - suburban. 


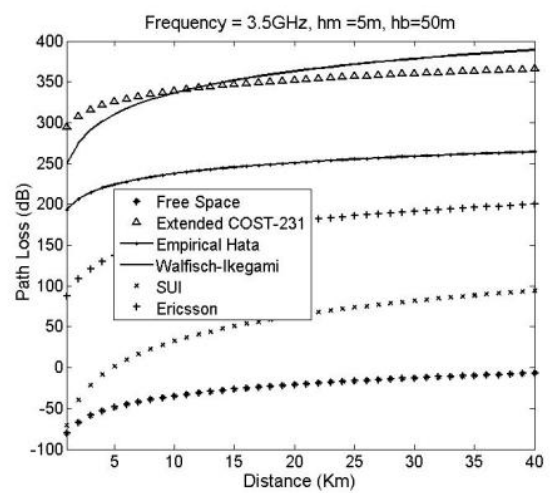

Fig. 5: Path loss against distance - urban.

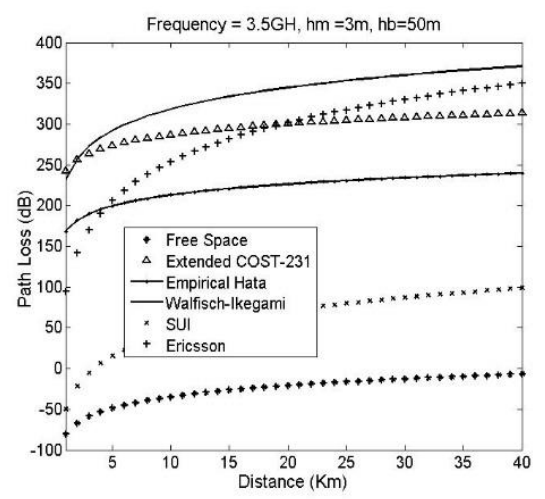

Fig. 6: Path loss against distance - suburban.

Figures 7 and 8 show the path loss comparison for three models: SUI, Ericsson and Empirical Hata in urban and suburban environments respectively. The average path loss of the three tested models is shown in Table 3 . It can be seen that the average path loss for SUI is 30 in urban while it is 18.55 in suburban environment. From the obtained results, it is concluded that on Frequency of $3.5 \mathrm{GHz}$ with $h m=5 \mathrm{~m}$ and $h b=50 \mathrm{~m}$, the SUI model outperforms Ericsson and Empirical Hata in both urban and suburban environment.

Table 3: The average path loss against distance for 3 models $(3.5 \mathrm{GHz})$.

\begin{tabular}{|c|c|c|c|}
\hline Frequency $\mathbf{=} \mathbf{3 . 5} \mathbf{~ G H z}$ & Ericsson Model & SUI & Empirical HATA \\
\hline Suburban & 228.53 & 30.00 & 196.92 \\
\hline Urban & 139.55 & 18.55 & 221.63 \\
\hline
\end{tabular}

Figures 9 and 10 show the average path loss of three models tested on $28 \mathrm{GHz}$ in urban and suburban environment. In suburban environment, SUI model is shown to be the best with the lowest average path loss, while in urban environment Ericsson model shown to be the best with average path loss of 49.17 which is significantly better result compared to SUI and Empirical HATA averages as it is shown in Table 4. 
Table 4: The average path loss against distance for 3 models $(28 \mathrm{GHz})$.

\begin{tabular}{|c|c|c|c|}
\hline Frequency $=\mathbf{2 8} \mathbf{~ G H z}$ & Ericsson Model & SUI & Empirical HATA \\
\hline Suburban & 138.15 & 84.07 & 243.00 \\
\hline Urban & 49.17 & 72.62 & 276.03 \\
\hline
\end{tabular}

\section{Conclusion}

In this paper, PL prediction models in wireless mobile networks have been investigated. Different PL models are tested, such as: free space, extended COST-231 Hata model, empirical Hata model, Walfisch-Ikegami propagation model, Stanford University Interim (SUI) Model and Ericson (9999) model. The comparison is based on the path loss values for all models. To verify the results, the average path loss is introduced. It is found that on lower frequencies, SUI, Ericsson and Empirical Hata are overall good choices for the new generation of mobile networks regardless of the distance and the type of environment. Additionally, SUI outperforms Ericsson and Empirical Hata on $3.5 \mathrm{GHz}$ in both urban and suburban environment. On the other hand, on higher frequencies (i.e. $28 \mathrm{GHz}$ ), which is needed for the new generation of mobile networks like 5G, it is shown that Ericsson model gives better results for path loss in urban compared with SUI which gives better results in suburban environment. Both findings are confirmed by comparing the average path loss. The work can be extended in the future to include more investigation and analysis about higher frequencies in the future of $5 \mathrm{G}$ generation networks.

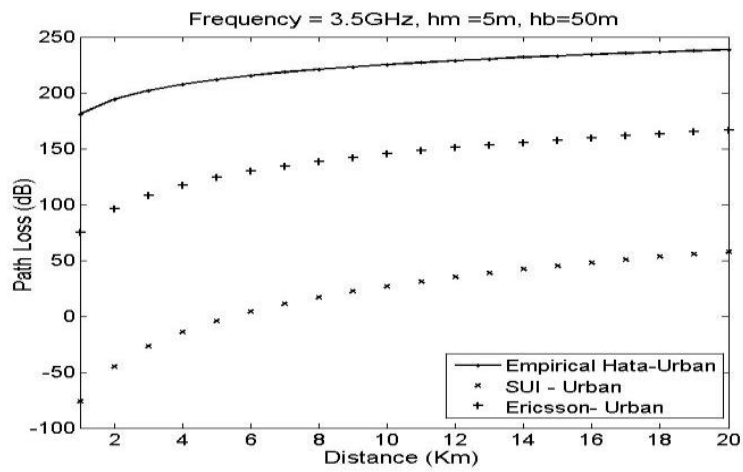

Fig. 7: Path loss against distance for 3 models - urban.

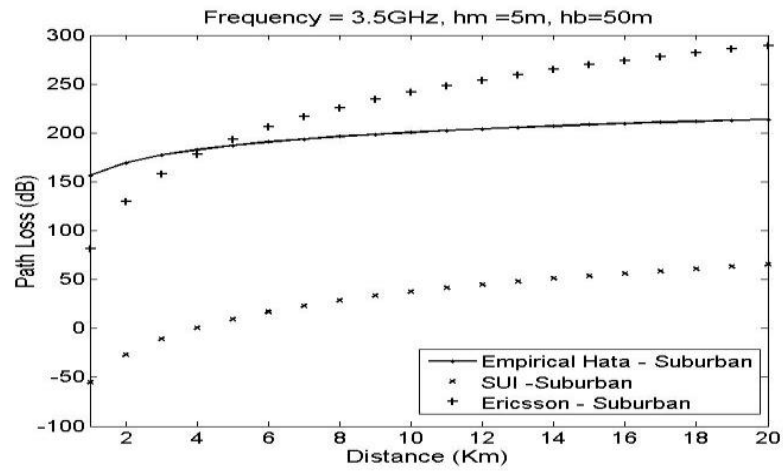

Fig. 8: Path loss against distance for 3 models - suburban. 


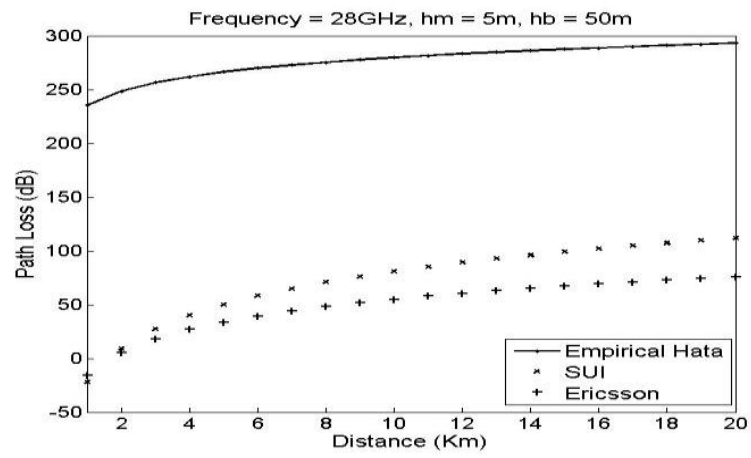

Fig. 9: Path loss against distance for 3 models - urban.

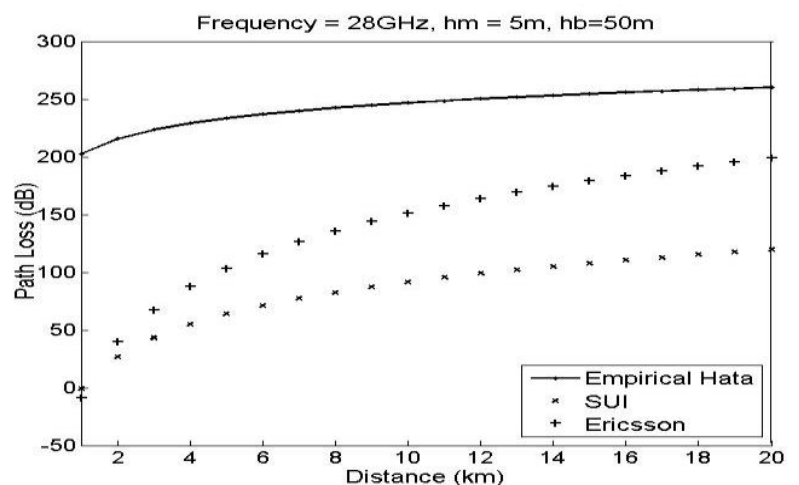

Fig. 10: Path loss against distance for 3models - suburban.

\section{Acknowledgements}

We would like to thank American University of the Middle East (AUM) for the Sponsorship and financial support.

\section{References}

[1] V. S. Abhayawardhana, I. J. Wassel, D. Crosby, M. P. Sellers, and M. G., Brown, "Comparison of empirical propagation path loss models for fixed wireless access systems," 61th IEEE Technology Conference, Stockholm, vol. 1, pp. 73-77, http://dx.doi.org/10.1109/vetecs.2005.1543252, 2005.

[2] Y. Singh, "Comparison of Okumura, Hata and COST-231 Models on the Basis of Path Loss and Signal Strength," International Journal of Computer Applications, vol. 59, no. 11, pp. 37-41, 2012.

[3] T. S. Rappaport, Wireless communications: principles and practice. 2nd. Ed, Prentice Hall, New Delhi, 2005.

[4] P. M. Ghosh, M. A. Hossain, Zainul-Abadin, K. K. Karmakar, "Comparison among different large scale path loss models for high sites in urban, suburban and rural areas," International Journal of Soft Computing and Engineering (IJSCE), vol. 2, no. 2, pp. 287-290, 2012.

[5] P. K. Sharma and R. K. Singh, "Comparative Analysis of Propagation Path loss models with Field Measured Data," International Journal of Engineering Science and Technology, vol. 2, no. 6, pp. 2008-2013, 2010.

[6] V. Erceg, L. J. Greenstein, S. Tjandra, S. R. Parkoff, A. Gupta, B. Kulic, A. Julius, R. Jastrzab, "An empirically based path loss model for wireless channels in suburban environments," Global Telecommunication Conference, vol. 2, pp. 922-927, 1998.

[7] Cost Final Report, http://www.lx.it.pt/cost231 (Retrieved 1/11/2016).

[8] A. Zreikat, K. Al-Begain, K. Smith, "Comparative Capacity/Coverage Analysis of CDMA Cell in Different Propagation Environments," Wireless Personal Communications, vol. 28, no. 3, pp. 205-23, 2004.

[9] Z. Nadir \& M. Idrees Ahmad, "Path loss Determination Using Okumura-Hata Model and Cubic Regression for Missing Data for Oman,” Proceeding of IMECS, Hong Kong, vol. 2, 2010. 
[10] H. K. Sharma, S. H. Sahu \& S. Sharma, "Enhanced cost 231 propagations model in wireless network," International journal of computer application, vol. 19, no. 06, pp. 0975-8887, 2011.

[11] P. K. Sharma \& R. K. Singh, "Comparative Analysis of Propagation Path loss Models with Field Measured Data," International Journal of Engineering Science and Technology, vol. 2, no. 6, pp 2008-2013, 2010.

[12] T. Siva Priya, R. Mardeni, "Optimised COST-231 Hata Models for WiMAX Path Loss Prediction in Suburban and Open Urban Environments," Modern Applied Science, vol. 4, no. 9, pp. 75-89, 2010.

[13] N. S Nkordeh, A. A. A Atayero, F. E Idachaba, O. O. Oni, "LTE Network Planning using the Hata-Okumura and the COST-231 Hata Pathloss Models," Proceedings of the World Congress on Engineering, London, U.K., vol. 1, 2014.

[14] V. S. Abhayawardhana, I. J. Wassell, D. Crosby, M. P. Sellars, M. G. Brown, "Comparison of propagation Models accuracy for WIMAX on 3.5GHz," Proceedings of 2007 IEEE International Conference on ELECTRONICS, CIRCUITS AND SYSTEMS, Maroko, pp. 111-114, 2007.

[15] M. S. Mollel, M. Kisangiri, "Comparison of Empirical Propagation Path Loss Models for Mobile Communication. Computer Engineering and Intelligent systems," vol. 5, no. 9, pp. 1-10, 2014.

[16] A. I. Sulyman, A. T. Nassar, M. K. Samimi, G. R. Maccartney, T. S. Rappaport, A. Alsanie, "Radio propagation path loss models for $5 \mathrm{G}$ cellular networks in the $28 \mathrm{GHz}$ and $38 \mathrm{GHz}$ millimeter-wave bands," IEEE Communications Magazine, vol. 52, no. 9, pp. 78-86, 2014.

[17] A. N. Jadhav, S. S. Kale, "Suburban Area Path loss Propagation Prediction and Optimization Using Hata Model at $2375 \mathrm{MHz}$," International Journal of Advanced Research in Computer and Communication Engineering, vol. 3, no. 1, pp. 5004-5008.

[18] K. A. Akpado, O. S. Oguejiofor, C. O. Ezeagwu, A. U. Okolibe, "Investigating the Impacts of Base Station Antenna Height, Tilt and Transmitter Power on Network Coverage," International Journal of Engineering Science Invention, vol. 2, no. 7, pp. 32-38, 2013. 